\title{
Biomarker Analysis Revealed Distinct Profiles of Innate and Adaptive Immunity in Infants with Ocular Lesions of Congenital Toxoplasmosis
}

\author{
Anderson Silva Machado, ${ }^{1}$ Ana Carolina Aguiar Vasconcelos Carneiro, ${ }^{1}$ \\ Samantha Ribeiro Béla, ${ }^{2}$ Gláucia Manzan Queiroz Andrade, ${ }^{3}$ \\ Daniel Vitor Vasconcelos-Santos, ${ }^{4}$ José Nélio Januário, ${ }^{5}$ \\ Jordana G. Coelho-dos-Reis, ${ }^{2}$ Eloisa Amália Vieira Ferro, ${ }^{6}$ Andréa Teixeira-Carvalho, ${ }^{2}$ \\ Ricardo Wagner Almeida Vitor, ${ }^{1}$ Olindo Assis Martins-Filho, ${ }^{2}$ \\ and UFMG Congenital Toxoplasmosis Brazilian Group - UFMG-CTBG ${ }^{5}$ \\ ${ }^{1}$ Departamento de Parasitologia, Universidade Federal de Minas Gerais, Avenida Presidente Antônio Carlos, 6627, Pampulha, \\ 31270-901 Belo Horizonte, MG, Brazil \\ ${ }^{2}$ Laboratório de Biomarcadores de Diagnóstico e Monitoração, Centro de Pesquisas René Rachou, Fundação Oswaldo Cruz, \\ Avenida Augusto de Lima, 1715 Barro Preto, 30190-002 Belo Horizonte, MG, Brazil \\ ${ }^{3}$ Departamento de Pediatria, Universidade Federal de Minas Gerais, Avenida Professor Alfredo Balena 190, Santa Efigênia, \\ 30130-100 Belo Horizonte, MG, Brazil \\ ${ }^{4}$ Departamento de Oftalmologia e Otorrinolaringologia, Faculdade de Medicina da UFMG, Belo Horizonte, MG, Brazil \\ ${ }^{5}$ Núcleo de Ações e Pesquisa em Apoio Diagnóstico (NUPAD), Universidade Federal de Minas Gerais, \\ Avenida Professor Alfredo Balena 190, Santa Efigênia, 30130-100 Belo Horizonte, MG, Brazil \\ ${ }^{6}$ Universidade Federal de Uberlândia, Avenida João Naves de Ávila 2121, Santa Mônica, 38408-100 Uberlândia, MG, Brazil
}

Correspondence should be addressed to Olindo Assis Martins-Filho; oassismartins@gmail.com

Received 24 May 2014; Revised 14 July 2014; Accepted 18 July 2014; Published 18 September 2014

Academic Editor: Edecio Cunha-Neto

Copyright (C) 2014 Anderson Silva Machado et al. This is an open access article distributed under the Creative Commons Attribution License, which permits unrestricted use, distribution, and reproduction in any medium, provided the original work is properly cited.

\begin{abstract}
Toxoplasma gondii is the main infectious cause of human posterior retinochoroiditis, the most frequent clinical manifestation of congenital toxoplasmosis. This investigation was performed after neonatal screening to identify biomarkers of immunity associated with immunopathological features of the disease by flow cytometry. The study included infected infants without NRL and with retinochoroidal lesions (ARL, ACRL, and CRL) as well as noninfected individuals (NI). Our data demonstrated that leukocytosis, with increased monocytes and lymphocytes, was a relevant hematological biomarker of ARL. Immunophenotypic analysis also revealed expansion of $\mathrm{CD}_{1} 4^{+} \mathrm{CD} 16^{+} \mathrm{HLA}-\mathrm{DR}{ }^{\text {high }}$ monocytes and $\mathrm{CD} 56^{\mathrm{dim}}$ cytotoxic NK-cells in ARL. Moreover, augmented $\mathrm{TCR} \gamma \delta^{+}$and $\mathrm{CD}^{+} \mathrm{T}$-cell counts were apparently good biomarkers of morbidity. Biomarker network analysis revealed that complex and intricated networks underscored the negative correlation of monocytes with NK- and B-cells in NRL. The remarkable lack of connections involving B-cells and a relevant shift of NK-cell connections from B-cells toward T-cells observed in ARL were outstanding. A tightly connected biomarker network was observed in CRL, with relevant connections of NK- and CD8 ${ }^{+} \mathrm{T}$-cells with a broad range of cell subsets. Our findings add novel elements to the current knowledge on the innate and adaptive immune responses in congenital toxoplasmosis.
\end{abstract}

\section{Introduction}

Ocular toxoplasmosis is a common inflammatory eye disease and a major cause of posterior uveitis worldwide [1].
The importance of toxoplasmosis is even greater in Brazil, where the prevalence and severity of ocular disease are higher than those in the rest of the world [2]. A study conducted in Brazil showed that $90 \%$ of newborns with congenital 
toxoplasmosis had clinical signs at birth. The main symptom observed was retinochoroiditis, present in $80 \%$ of newborns [3].

The success of infection caused by T. gondii is based on a delicate balance between the host immune response, which tries to clear the parasite, and the immune evasion strategies or immunomodulation elicited by the parasite, which enables the ultimate survival of both the parasite and the host [4]. A number of different host cells and compartments are involved in the immune response to T. gondii, and the interplay between these cells is crucial to resistance to the parasite [59].

Scarce immunological data on ocular disease in humans is available and these studies have mainly focused on the T. gondii-specific T-cell response in vitro. The analysis of systemic specific cellular response to $T$. gondii antigen in patients without and with active/cicatricial ocular lesions in acquired or congenital disease has described controversial data on the role of proinflammatory response in this scenario. Yamamoto and colleagues have characterized the immune response in adult patients with ocular disease due to congenital infection and have suggested that these patients may show tolerance toward the parasite by decreased proinflammatory response along with lower lymphoproliferative index [10]. In contrast, Fatoohi and colleagues show that systemic cellular response to $T$. gondii does not differ between adult patients without and with presumed congenital ocular toxoplasmosis in regard to T-cell activation and proinflammatory cytokine production [11]. Despite recent advances in toxoplasmosis immunology, relatively little attention has been focused on the immunological events related to the congenital toxoplasmic retinochoroiditis in infant patients. Considering these previous reports, this work aimed at characterizing the ex vivo systemic immunophenotypic profile of innate and adaptive cell subsets during the early phases of congenital toxoplasmosis and its association with the absence/presence of active/cicatricial retinochoroiditis in infants.

\section{Methods}

2.1. Study Population. The protocols conducted in this study were approved by the local Ethics Committee (Federal University of Minas Gerais, protocol 298/06) and written informed consent was obtained from all mothers of infants included in this study.

This study was part of a prospective investigation on neonatal screening for congenital toxoplasmosis conducted by a multidisciplinary research group (UFMG Congenital Toxoplasmosis Brazilian Group). From November 1, 2006, to May 31, 2007, a total of 146,307 children were tested for anti-T. gondii IgM antibodies in dried blood samples on filter paper using the Toxo IgM kit (Q-Preven, Symbiosis, Leme, Brazil). Confirmative plasma/serum tests were run in 220 infants and their mothers in cases with positive or underterminated screening results. The mothers and infants were tested for IgA (enzyme-linked immunosorbent assay) and IgG and IgM anti-T. gondii (enzyme-linked fluorometric assay, ELFA-VIDAS, BioMérieux SA, Lyon, France). Out of these 220 cases, 190 infants tested positive by confirmative exams and for the persistence of anti-T. gondii IgG antibodies in serum at the age of 12 months. All infants included in this study received medical care by a general clinical physician with experience with infectious diseases and the physical examination did not reveal any alteration. Ophthalmologic evaluation was performed by two retina/uveitis specialists assisted by a trained nursing professional according to a standardized protocol as reported elsewhere [3]. Infants also underwent a through pediatric examination, neuroimaging studies (cranial radiographs or transfontanel ultrasound; computer-assisted tomography in selected cases), hearing assessment, and ophthalmologic evaluation. Peripheral blood samples from 105 infants ( $45 \pm 12$ days of age; $53 \%$ male, $47 \%$ female) were collected to obtain leukocytes. These infants were classified into two groups: (i) group TOXO (infected infants), which comprised 83 infants diagnosed with congenital toxoplasmosis who had positive confirmative tests and persistent specific IgG antibodies, and (ii) group NI (control noninfected infants), which comprised 22 infants who tested negative by IgG anti-T. gondii. Among the 83 children from group TOXO, 15 infants presented active retinochoroidal lesions (ARL), 27 had simultaneous active and cicatricial retinochoroidal lesions (ACRL), 17 had cicatricial retinochoroidal lesions (CRL), and 24 had no retinochoroidal lesions (NRL). Infants from the NI group did not have any type of retinochoroidal lesions.

2.2. Flow Cytometric Acquisition and Analysis. Peripheral blood from infants with congenital toxoplasmosis (TOXO) and noninfected infants (NI) was processed, and leukocyteswere used for ex vivo protocols, as previously described [10]. Monoclonal antibodies (mAbs) were used for labeling cell surface molecules, for $\mathrm{T}$ and $\mathrm{NKT}$ lymphocytes (anti-CD3, anti-CD4, and anti-CD8), B lymphocytes (antiCD5, anti-CD19, and anti-CD23), monocytes (anti-CD14, anti-CD16, anti-CD32, and anti-CD64), NK- and NKT-cells (anti-CD16, anti-CD56), anti-HLA-DR (activation), conventional T-cells (anti-TCR $\alpha \beta$ ), and gamma-delta T-cells (anti$\mathrm{TCR} \gamma \delta$ ), labeled with fluorescein isothiocyanate (FITC), phycoerythrin (PE), or TRI-COLOR (TC), which were purchased from Invitrogen Life Technologies (Carlsbad, CA, USA).

Cytofluorimetric data acquisition was performed with a Becton Dickinson FACSCalibur instrument. CELLQUEST software provided by the manufacturer was used for data analysis.

2.3. Data Analysis. This was a descriptive transversal study that applied three data analysis approaches for observational investigation of the immunological profile associated with distinct clinical manifestations of congenital toxoplasmosis, referred to as (1) conventional statistical analysis, (2) biomarker signature analysis, and (3) biomarkers network. The two later approaches have been shown as relevant to detect, with high sensitivity, putative minor changes in the immunological profiles that are not detectable by conventional statistical approaches. 
2.3.1. Conventional Statistical Analysis. Statistical analyses were conducted using GraphPad Prism 5.0 software (GraphPad Software, San Diego, CA, USA). Differences between groups were first evaluated to test the normality. Considering the nonparametric nature of all data sets, statistical analyses between the TOXO and NI groups were performed by the Mann-Whitney test. Additional analyses among the TOXO subgroups were performed by the Kruskal-Wallis test, followed by Dunns' multiple comparison test. Data sets are presented as scatter distributions over median values (bars) for TOXO and NI groups. Data from the TOXO subgroups analysis were presented in box-plot format, highlighting the median together with the minimum and maximum values. In all cases, differences were considered significant at $P<0.05$.

2.3.2. Biomarker Signature Analysis. The use of this approach was adapted from a pioneering study in order to identify relevant differences in the peripheral blood phenotypic signatures between the groups [11]. In this data analysis, initially, the whole universe of data of each cell subset was used to calculate the global median value used as the cut-off to classify infants as with "low" or "high" counts of a given biomarker. The following cut-offs were used to categorize each infant as presenting "low" or "high" levels of a given cell subset: $\mathrm{MONCD16}{ }^{+}=125.0$ cells $/ \mathrm{mm}^{3}$, MONCD16 ${ }^{+} \mathrm{DR}^{\text {high }}=86.2$ cells $/ \mathrm{mm}^{3}, \mathrm{MONCD}^{+}=78.8$ cells $/ \mathrm{mm}^{3}$, MONCD64 $4^{+}=186.6$ cells $/ \mathrm{mm}^{3}$, NK-cells = 1195.2 cells $/ \mathrm{mm}^{3}$, NKCD16 ${ }^{+} \mathrm{CD} 56^{-}=441.2$ cells $/ \mathrm{mm}^{3}$,

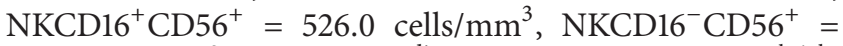
85.4 cells $/ \mathrm{mm}^{3}, \mathrm{CD}^{-} \mathrm{CD} 56^{\mathrm{dim}}=2.43 \%, \mathrm{CD}^{-} \mathrm{CD} 56^{\text {bright }}$ $=1.06 \%, \mathrm{CD}^{+} \mathrm{CD}^{+} 6^{+}=73.8$ cells $/ \mathrm{mm}^{3}$, NKT-cells $=50.3$ cells $/ \mathrm{mm}^{3}, \mathrm{CD}^{+}=4590.5$ cells $/ \mathrm{mm}^{3}, \mathrm{TCR} \alpha \beta^{+}=3991.6$ cells $/ \mathrm{mm}^{3}, \mathrm{TCR} \gamma \delta^{+}=452.4$ cells $/ \mathrm{mm}^{3}, \mathrm{TCD}^{+}=2850.2$ cells $/ \mathrm{mm}^{3}, \mathrm{TCD}^{+}=1862.6$ cells $/ \mathrm{mm}^{3}, \mathrm{TCD}^{+} \mathrm{CD}^{+}=38.8$ cells $/ \mathrm{mm}^{3}, \mathrm{TCD}^{+} \mathrm{DR}^{+}=466.5$ cells $/ \mathrm{mm}^{3}, \mathrm{TCD}^{+} \mathrm{DR}^{+}=$

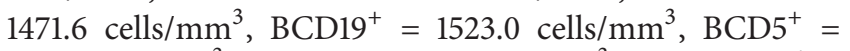
851.3 cells $/ \mathrm{mm}^{3}, \mathrm{BCD} 5^{-}=576.7$ cells $/ \mathrm{mm}^{3}$, and BCD23 $3^{+}=$ 959.0 cells $/ \mathrm{mm}^{3}$. Once the cut-offs for each biomarker were established, we selected infants with high biomarker counts and assembled the data using gray-scale diagrams to calculate the frequency of those for each clinical group. Relevant data $(>50 \%)$ were then highlighted in bold/underline format. Radar charts were constructed to characterize the overall frequency of infants with high levels of a given innate or adaptive immune cell population. GraphPad Prism 5.00 software (San Diego, USA) was used for graphical arts.

2.3.3. Biomarker Network. Biomarker networks were assembled to assess the association between cell subpopulations (monocytes, NK-cells, NKT-cells, T-cells, and B-cells) and their subsets for each clinical group. The correlations were significant when Spearman's test resulted in a $P<0.05$. Significant correlations representing the interaction between biomarkers tested were compiled using the open source software Cytoscape (version 2.8; http://www.cytoscape.org), as previously reported [12]. Biomarker networks were constructed using circle layouts with each biomarker being represented by a specific cartoon (monocytes; NK- and NKT-cells;
T-cells and B-cells). Connecting edges display the underscore as negative, moderate, and strong, as proposed previously [13]. The correlation index $(r)$ was used to categorize the correlation strength as negative $(r<0)$, moderate $(0.36>$ $r<0.67)$, or strong $(r>0.68)$. GraphPad Prism 5.00 software (San Diego, USA) was used for the data analysis.

\section{Results}

3.1. Leukocytosis with Increased Monocyte and Lymphocyte Counts is a Relevant Hematological Biomarker of Active Retinochoroidal Lesions in Congenital Toxoplasmosis. The analysis of hematological parameters demonstrated that TOXO is accompanied by relevant leukocytosis with increased monocyte and lymphocyte counts. Further categorization of infants, according to their ophthalmological records, showed that these changes were particularly observed in ARL patients. Relevant monocytosis was also observed in ACRL patients. No significant differences were observed in the NRL and CRL subgroups (Table 1).

3.2. Expansion of $C D 14^{+} \mathrm{CD} 16^{+} \mathrm{HLA}-\mathrm{DR} \mathrm{R}^{\text {high }}$ Proinflammatory Monocytes Is Present in Infants with Active Retinochoroidal Lesions in Congenital Toxoplasmosis. When evaluating monocyte subsets, our results demonstrated that infants in the TOXO group presented an increase of $\mathrm{CD}_{1}{ }^{+} \mathrm{CD} 16^{+}$ macrophage-like and $\mathrm{CD} 14^{+} \mathrm{CD} 16^{+} \mathrm{HLA}-\mathrm{DR}^{\text {high }}$ proinflammatory monocytes (Figure 1(a)). In fact, the increase in $\mathrm{CD}_{14}{ }^{+} \mathrm{CD} 16^{+}$HLA-DR ${ }^{\text {high }}$ proinflammatory monocytes was particularly observed in the ARL subgroup when compared with NI controls (Figure 1(a)).

Furthermore, analysis of FC $\gamma$-R expression by monocytes (Figure 1(b)) showed that TOXO displayed relevant changes in CD32 and CD64 expression on the surface of these cells. Analysis of the TOXO subgroups demonstrated that the CRL infants, in particular, had decreased CD32 and increased CD64 expression when compared with NI control group (Figure 1(b)). Figure 1(c) shows representative flow cytometric histogram analyses of the CD32 and CD64 expression observed in the TOXO and NI groups.

3.3. NK- and NKT-Cell Subsets Are Expanded in the Peripheral Blood of Infants with Congenital Toxoplasmosis. Data regarding total $\mathrm{CD}^{-} \mathrm{CD}_{16}{ }^{+/-} \mathrm{CD} 56^{+/-}$NK-cells revealed an increased absolute count in peripheral blood samples from the TOXO group. Analysis of NK-cell subsets showed an increase in all NK-cell subsets in the TOXO group, including $\mathrm{CD}^{-} \mathrm{CD} 6^{+} \mathrm{CD} 56^{-}, \mathrm{CD}^{-} \mathrm{CD} 6^{+} \mathrm{CD} 56^{+}$, and $\mathrm{CD}^{-} \mathrm{CD}_{16}{ }^{-} \mathrm{CD} 56^{+}$cells (Figure 2(a)). Analysis of TOXO subgroups demonstrated that whereas total $\mathrm{CD}^{-} \mathrm{CD}^{-16^{+/-}} \mathrm{CD}^{-1 /-} \mathrm{NK}$-cells were enhanced in the ARL subgroup, $\mathrm{CD}^{-} \mathrm{CD}^{-} 6^{-} \mathrm{CD}^{+} 6^{+} \mathrm{NK}$-cells were expanded in the ACRL and CRL subgroups compared with the NI and NRL patients, respectively (Figure 2(a)).

Analysis of NKT-cell subsets showed a significant increase in both the $\mathrm{CD}^{+} \mathrm{CD}^{+} 6^{+}$and $\mathrm{CD}^{+} \mathrm{CD}^{2} 6^{+}$cell subpopulations in the TOXO group compared with the NI 


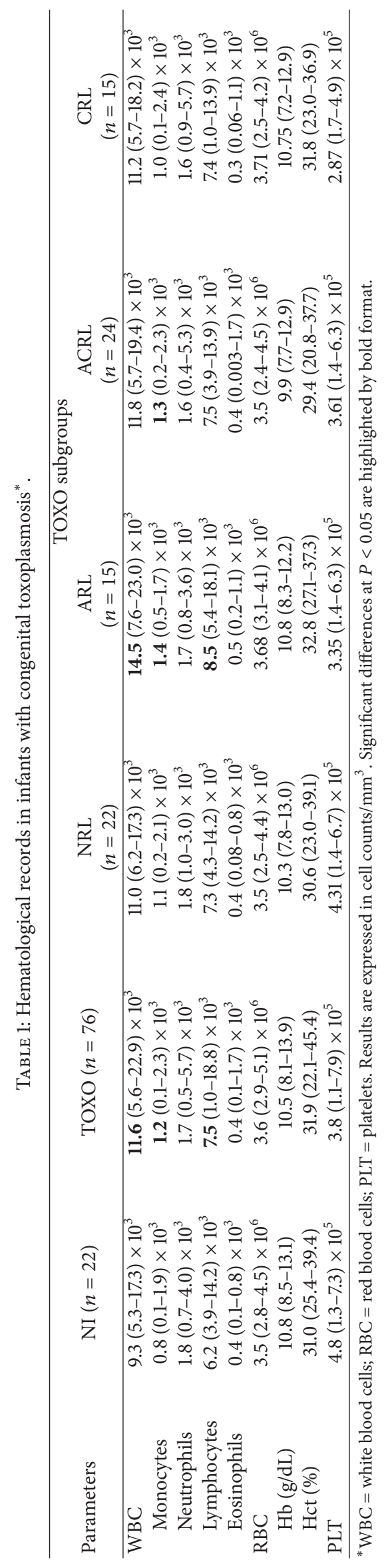




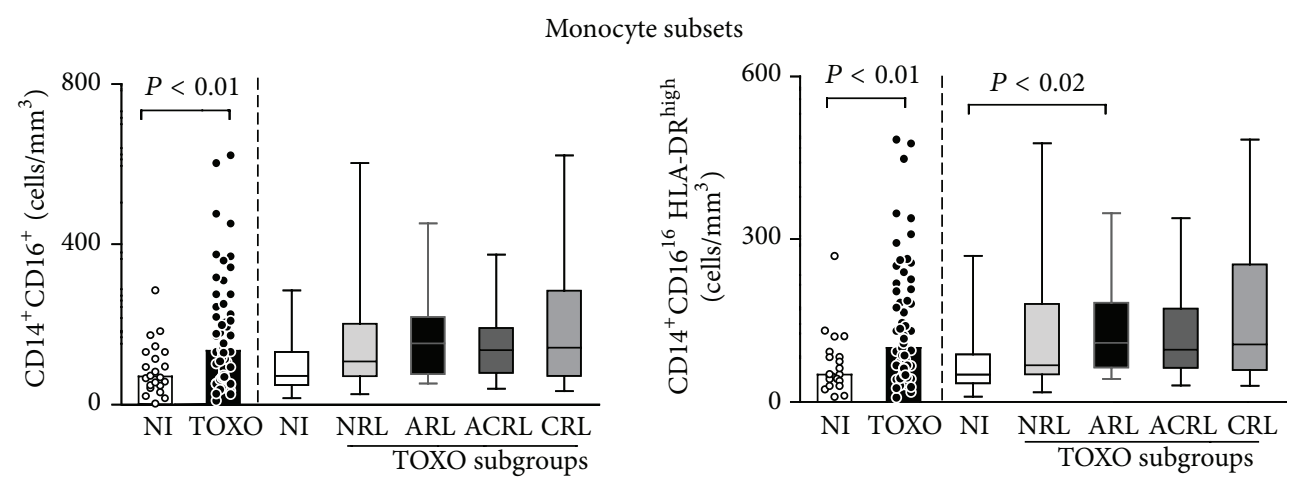

(a)
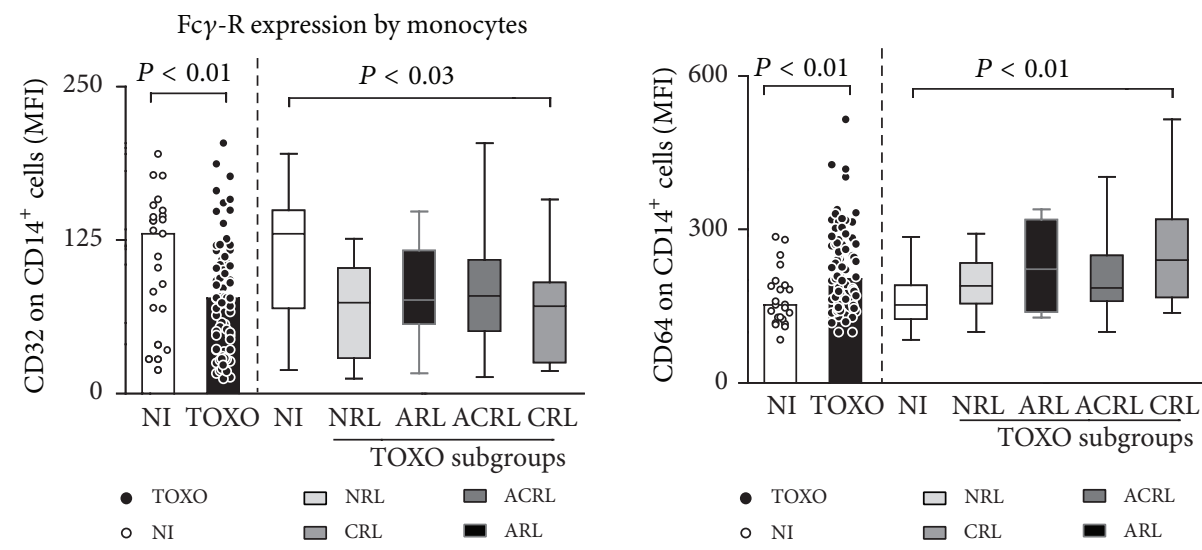

(b)

Representative flow cytometric histograms
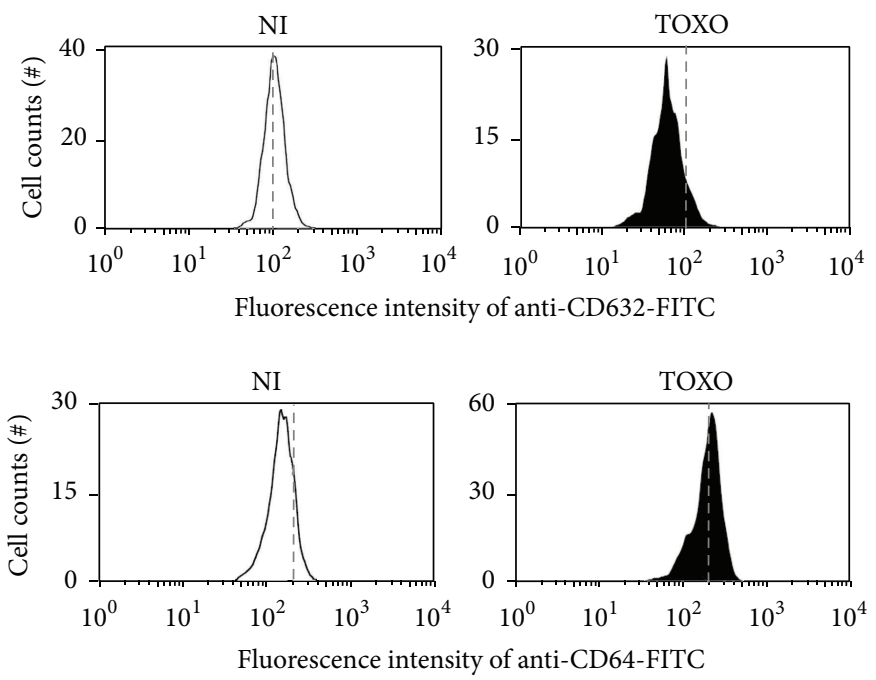

(c)

Figure 1: Monocyte subsets (a) and FC $\gamma$-R expression profile of monocytes (b) in the peripheral blood of congenital toxoplasmosis infants (TOXO) and noninfected controls (NI). Congenital toxoplasmosis was further categorized according to the clinical ocular status, referred to as no retinochoroidal lesions (NRL), active retinochoroidal lesions (ARL), active/cicatricial retinochoroidal lesions (ACRL), and cicatricial retinochoroidal lesions (CRL). The results are expressed as scatter plots of individual values and the medians of absolute cell counts $/ \mathrm{mm}^{3}$ (left side) or in box-plot format (right side), where the box stretches from the lower hinge (25th percentile) to the upper hinge (75th percentile), and the middle half represents the median of the distribution as a line across the box. Significant differences are highlighted by connecting lines, and $P$ values are shown in the figure. (c) Representative histograms illustrating the downregulation of CD32 (top panels) and the upregulation of CD64 (bottom panels) on circulating monocytes from infants with congenital toxoplasmosis (black) compared to noninfected controls (white). The dashed lines were set to highlight the shift in the histogram distribution toward lower or higher FC $\gamma$-R expression by monocytes. 
group. In fact, $\mathrm{CD}^{+} \mathrm{CD} 16^{+}$cells were particularly expanded in the ARL and ACRL subgroups, whereas $\mathrm{CD}^{+} \mathrm{CD} 56^{+}$cells were significantly increased in the ARL and CRL subgroups compared to NI controls (Figure 2(b)).

To characterize the major phenotypes related to the distinct functional features of NK-cells, we investigated the frequency of CD56 ${ }^{\mathrm{dim}}$ cytotoxic and CD56 ${ }^{\text {bright }}$ immunoregulatory cell subsets. Our findings demonstrated a decreased percentage of $\mathrm{CD}^{-} \mathrm{CD} 16^{+} \mathrm{CD} 56^{\text {bright }}$ cells along with the expansion of $\mathrm{CD}^{-} \mathrm{CD} 16^{+} \mathrm{CD} 56^{\text {dim }}$ cells in the TOXO group compared to the NI group. Additional analysis revealed that $\mathrm{CD} 3^{-} \mathrm{CD} 16^{+} \mathrm{CD} 56^{\text {bright }}$ cells were reduced in all TOXO subgroups, while $\mathrm{CD}^{-} \mathrm{CD}^{-} 6^{+} \mathrm{CD} 56^{\mathrm{dim}}$ cells were particularly expanded in the ARL subgroup compared to the NI group (Figure 2(a)).

\subsection{Augmented Activation of $\mathrm{CD} 4^{+} \mathrm{T}$-Cells is Closely Related} to the Presence of Active Retinochoroidal Lesions. Analysis of the adaptive immunity compartment is presented in Figure 3. Our data showed that TOXO patients presented increased counts of activated $\mathrm{CD} 4^{+} \mathrm{HLA}-\mathrm{DR}^{+}$T-cells along with $\mathrm{CD}_{4}^{+} \mathrm{CD}^{+}{ }^{+}$-cells, $\mathrm{CD} 19^{+} \mathrm{B}$-cells, and $\mathrm{CD} 19^{+} \mathrm{CD}^{+}{ }^{+} \mathrm{B1}-$ cells compared to NI patients (Figures 3(a) and 3(b)).

Additionally, our data demonstrated that $\mathrm{CD} 4^{+} \mathrm{T}$-cell counts were increased in the ARL subgroup compared to the CRL subgroup. Moreover, $\mathrm{CD} 4^{+} \mathrm{HLA}^{-} \mathrm{DR}^{+}$cells were particularly increased in the ARL and ACRL subgroups compared to the NI group (Figure 3(a)). No changes in Bcell subsets were observed among the TOXO subgroups (Figure 3(b)).

Our data demonstrated increased counts of TCR $\gamma \delta^{+}$cells, $\mathrm{CD}^{+}$T-cells, and particularly activated $\mathrm{CD} 8^{+} \mathrm{HLA}^{-} \mathrm{DR}^{+} \mathrm{T}-$ cells in the TOXO group. Analysis of TOXO subgroups demonstrated that TCR $\gamma \delta^{+}$cells, $\mathrm{CD} 8^{+} \mathrm{T}$-cells, and activated $\mathrm{CD}^{+}{ }^{+} \mathrm{HLA}-\mathrm{DR}^{+} \mathrm{T}$-cells, in particular, were increased in all groups with retinochoroidal lesions (ARL, ACRL, and CRL).

3.5. Expanded Frequency of Infants with High Levels of Innate and Adaptive Immune Cells Characterizes the Biomarker Signature Associated with the Presence of Active Retinochoroidal Lesions. To further characterize the immunological profile associated with distinct clinical manifestations of congenital toxoplasmosis, we assembled the overall phenotypic biomarker signature of peripheral blood innate/adaptive immune cells using the innovative/nonconventional data analysis approach referred to as the biomarker signature of innate and adaptive immunity compartments in the peripheral blood of infants with congenital toxoplasmosis (Figure 4).

Our data demonstrated that, in the NI group, most biomarkers were confined to frequencies below 50\%, except MONCD $32^{+}, \mathrm{CD} 3-\mathrm{CD} 56^{\text {bright }}$, and $\mathrm{CD}^{+}{ }^{+}$T-cells. However, in all TOXO subgroups, most biomarkers were confined to frequencies above $50 \%$. Specifically, the NRL subgroup predominantly showed enhancement of $\mathrm{B}$-cell related biomarkers $\left(\mathrm{BCD} 19^{+}, \mathrm{BCD}^{+}, \mathrm{BCD}^{-}\right.$, and $\mathrm{BCD} 23^{+}$) along with $\mathrm{TCD}^{+}, \mathrm{TCR} \gamma \delta^{+}$, and NKT-cells in the innate immune compartment. By contrast, the CRL subgroups predominantly showed increases in the frequency of innate immunity biomarkers (MONCD16 ${ }^{+}, \mathrm{MONCD}^{+} 6^{+} \mathrm{DR}^{\text {high }}$, $\mathrm{MONCD}^{+} 4^{+}, \mathrm{NK}$-cells, $\mathrm{CD} 16^{+} \mathrm{CD} 56^{-}, \mathrm{CD} 16^{+} \mathrm{CD} 56^{+}$, $\mathrm{CD}_{16}{ }^{-} \mathrm{CD} 56^{+}, \mathrm{CD}^{-} \mathrm{CD}^{-\mathrm{dim}}, \mathrm{CD}^{+} \mathrm{CD}^{+} 6^{+}$, and NKT-cells but not $\mathrm{MONCD}_{2} 2^{+}$and $\mathrm{CD}^{-} \mathrm{CD} 56^{\text {bright }}$ ) along with $\mathrm{T}$-cell related biomarkers $\left(\mathrm{TCR} \gamma \delta^{+}, \mathrm{TCD} 4^{+}, \mathrm{TCD}^{+}, \mathrm{TCD} 4^{+} \mathrm{CD} 8^{+}\right.$, and $\mathrm{TCD}^{+} \mathrm{DR}^{+}$).

The profile of the ARL subgroup was of particular interest, with an enhanced frequency of biomarkers in both the innate and adaptive immune compartments. All biomarkers included in this investigation were found to be increased to above $50 \%$ in the ARL infants evaluated, except for $\mathrm{MONCD}_{2}{ }^{+}$and $\mathrm{CD}^{-} \mathrm{CD} 56^{\text {bright }}$. The ACRL subgroup showed an overall biomarker signature similar to that observed in the ARL subgroup, with minor changes mainly in the NK- and B-cell subsets.

3.6. Remarkable Lack of Connections Involving B-Cells Is Observed in Infants with Active Retinochoroidal Lesions. Exploratory analysis of biomarker networks demonstrated that although some axes intrinsic of innate and adaptive immunity were preserved in all clinical groups, some connections were lost in the TOXO subgroups (Figure 5).

In the NI group, NK- and B-cells clearly represent relevant foci of connections. A relevant shift of NK-cell connections toward T-cells was observed in the ARL subgroup along with a selective loss of connections with the B-cell compartment (Figure 5).

The ACRL subgroup clearly showed a transitional profile between the ARL and CRL subgroups with NK-cell connections focusing on T-cells and restoring the connections with B-cells (Figure 5).

3.7. Complex and Imbricated Biomarker Networks Underscore the Interaction of Monocytes with NK- and B-Cells in Protective Events, Whereas NK-Cells and CD8 $8^{+}$T-Cells Appear Relevant to Mechanisms of Resolution. The fact that the NRL and CRL subgroups displayed a higher number of significant interactions and a more complex and imbricated biomarker network was outstanding. In fact, a rich number of connections were observed in these subgroups.

It was clear that the NRL subgroup showed relevant interaction between monocytes and other cell subsets (NKT-, $\mathrm{NK}-$, and B-cells) mediated by negative correlations and a relevant role of NK-cell connections focusing on T- and Bcells (Figure 5).

In the CRL subgroup, a strong correlation axis could be identified, with the pivotal participation of several NK-cell subsets interacting with T- and B-cells along with strong connections of $\mathrm{CD} 8^{+} \mathrm{T}$-cells with a broad range of cell subsets (Figure 5).

\section{Discussion}

Retinochoroiditis in humans caused by T. gondii is the most frequent clinical manifestation of congenital and acquired parasite infection $[14,15]$. The disease typically presents as a 
NK-cell subsets
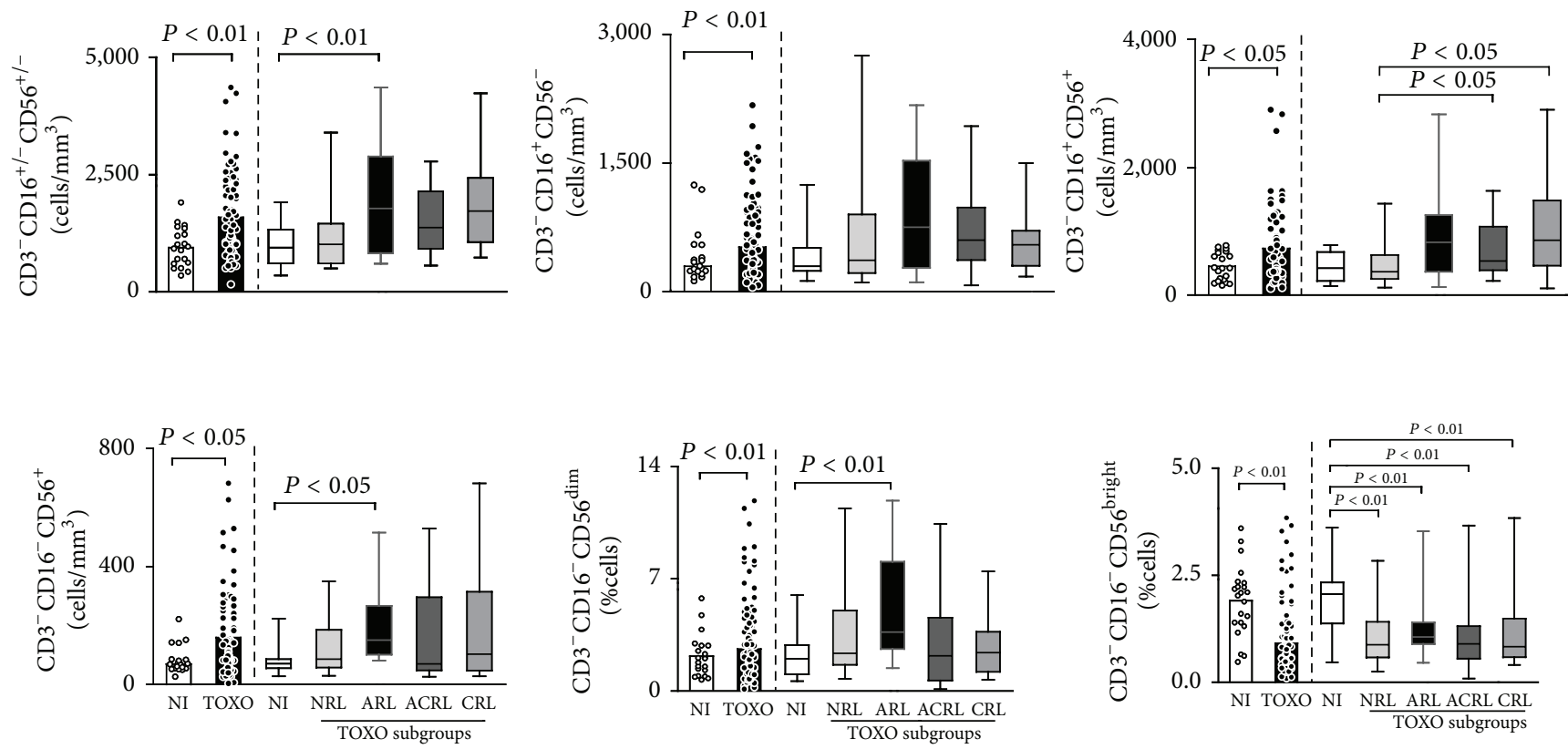

(a)

NKT-cell subsets
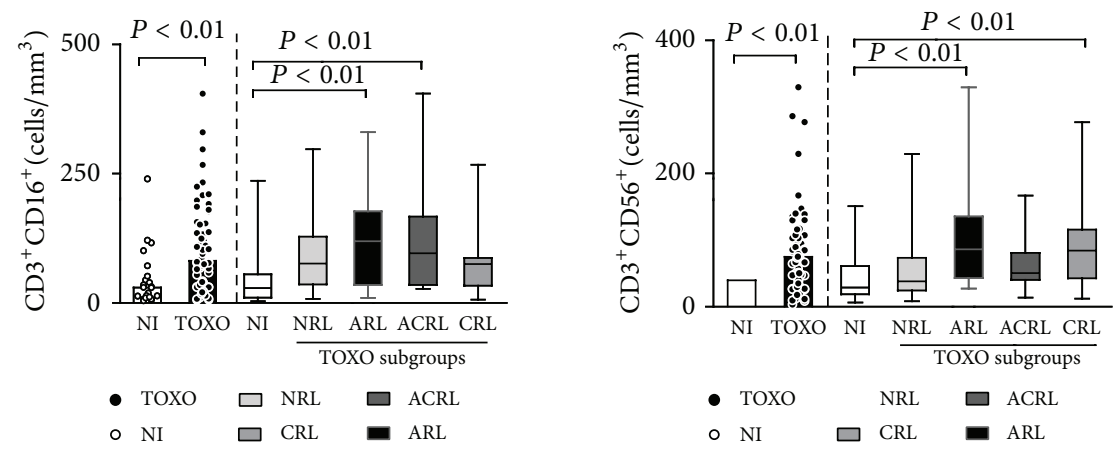

(b)

FIGURE 2: NK- (a) and NKT-cell subsets (b) in the peripheral blood of congenital toxoplasmosis infants (TOXO) and noninfected controls (NI). Congenital toxoplasmosis was further categorized according to the clinical ocular status, referred to as no retinochoroidal lesions (NRL), active retinochoroidal lesions (ARL), active/cicatricial retinochoroidal lesions (ACRL), and cicatricial retinochoroidal lesions (CRL). The results are expressed as scatter plots of individual values and the medians of absolute cell counts $/ \mathrm{mm}^{3}$ (left side) or in box-plot format (right side), where the box stretches from the lower hinge (25th percentile) to the upper hinge (75th percentile), and the middle half represents the median of the distribution as a line across the box. Significant differences are highlighted by connecting lines, and $P$ values are shown in the figure.

unilateral focal necrotizing lesion in the presence of adjacent scars [1].

The common occurrence of toxoplasmic retinochoroiditis is believed to be under the influence of the status of the host immune response [16], the genotype of infective parasite strains [2], and the host genetic background [17, 18]; however, the participation of cellular components that lead to the establishment of this ocular manifestation has not been addressed well in humans.
The presence of active, active/cicatricial, or cicatricial lesions observed in the infants of our cohort is consequence of multiple factors, which may include parasite virulence and retinotropism of T. gondii in Brazil, individual susceptibility as well as the $T$. gondii-specific immune response in the infants of our cohort. Another possibility is that the time of infection during pregnancy may impact the outcome of distinct retinochoroidal lesions. The premise that putative infection by parasites with diverse virulence 

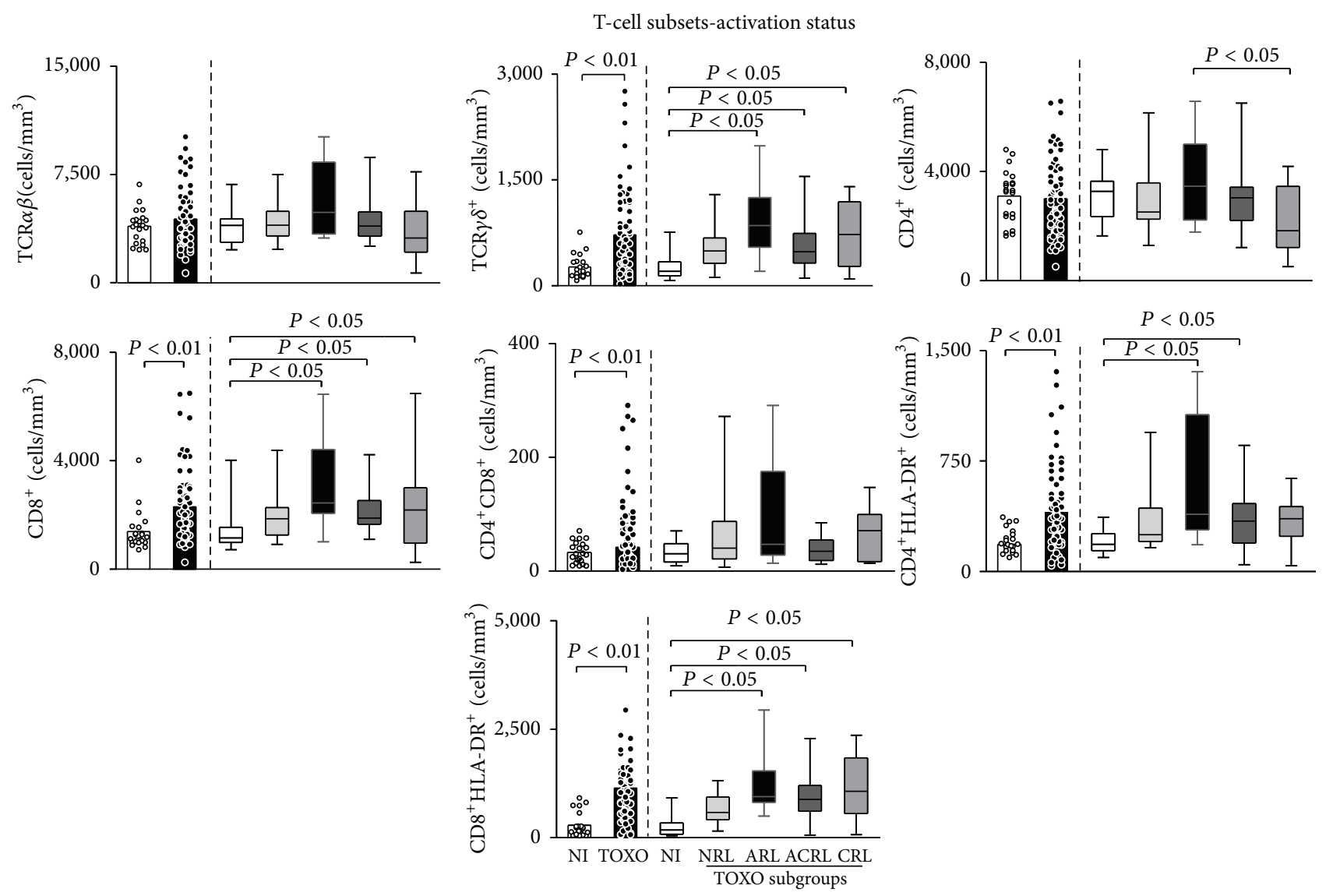

(a)

B-cell subsets-activation status
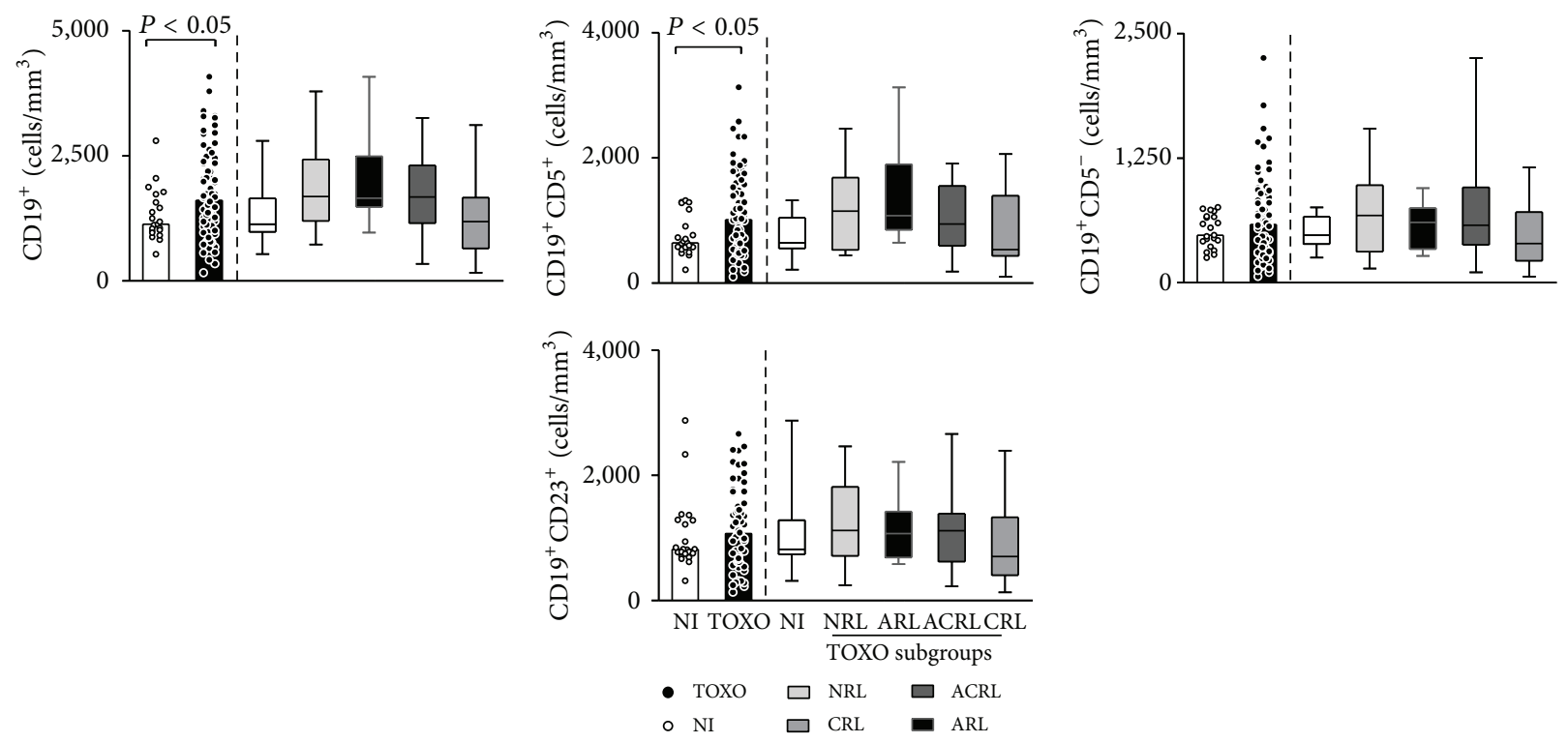

(b)

Figure 3: Major subsets and activation status of T- (a) and B-cells (b) in the peripheral blood of infants with congenital toxoplasmosis (TOXO) and noninfected controls (NI). Congenital toxoplasmosis was further categorized according to the clinical ocular status, referred to as no retinochoroidal lesions (NRL), active retinochoroidal lesions (ARL), active/cicatricial retinochoroidal lesions (ACRL), and cicatricial retinochoroidal lesions (CRL). The results are expressed as scatter plots of individual values and the medians of absolute cell counts/mm ${ }^{3}$ (left side) or in box-plot format (right side), where the box stretches from the lower hinge (25th percentile) to the upper hinge (75th percentile), and the middle half represents the median of the distribution as a line across the box. Significant differences are highlighted by connecting lines, and $P$ values are shown in the figure. 


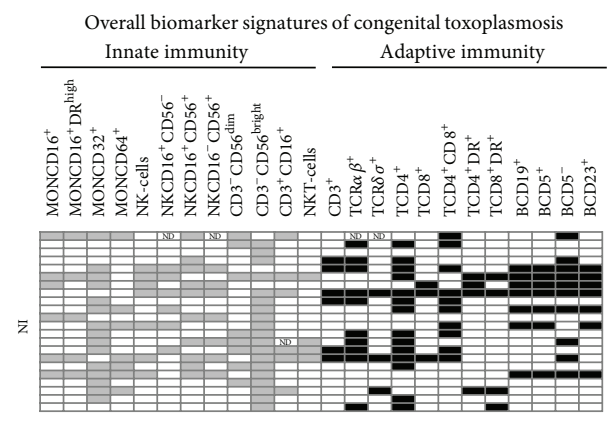

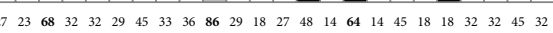

(\%)

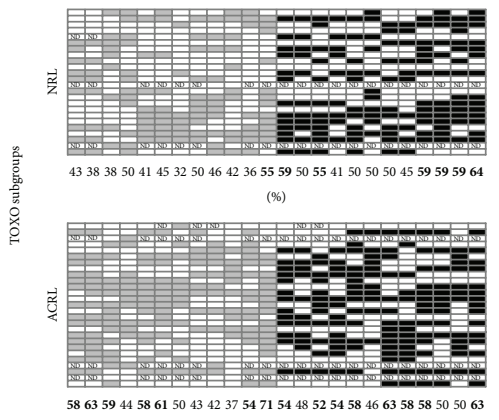

(\%)
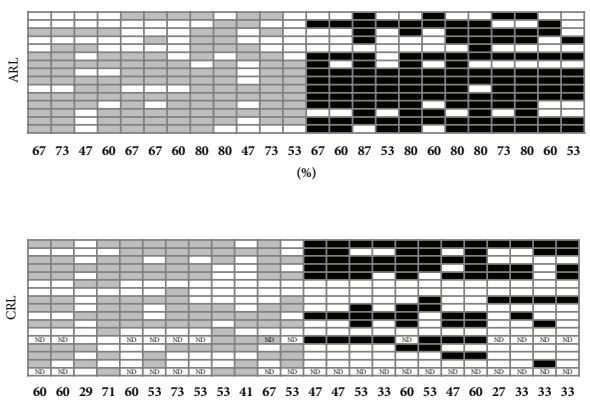

(a)
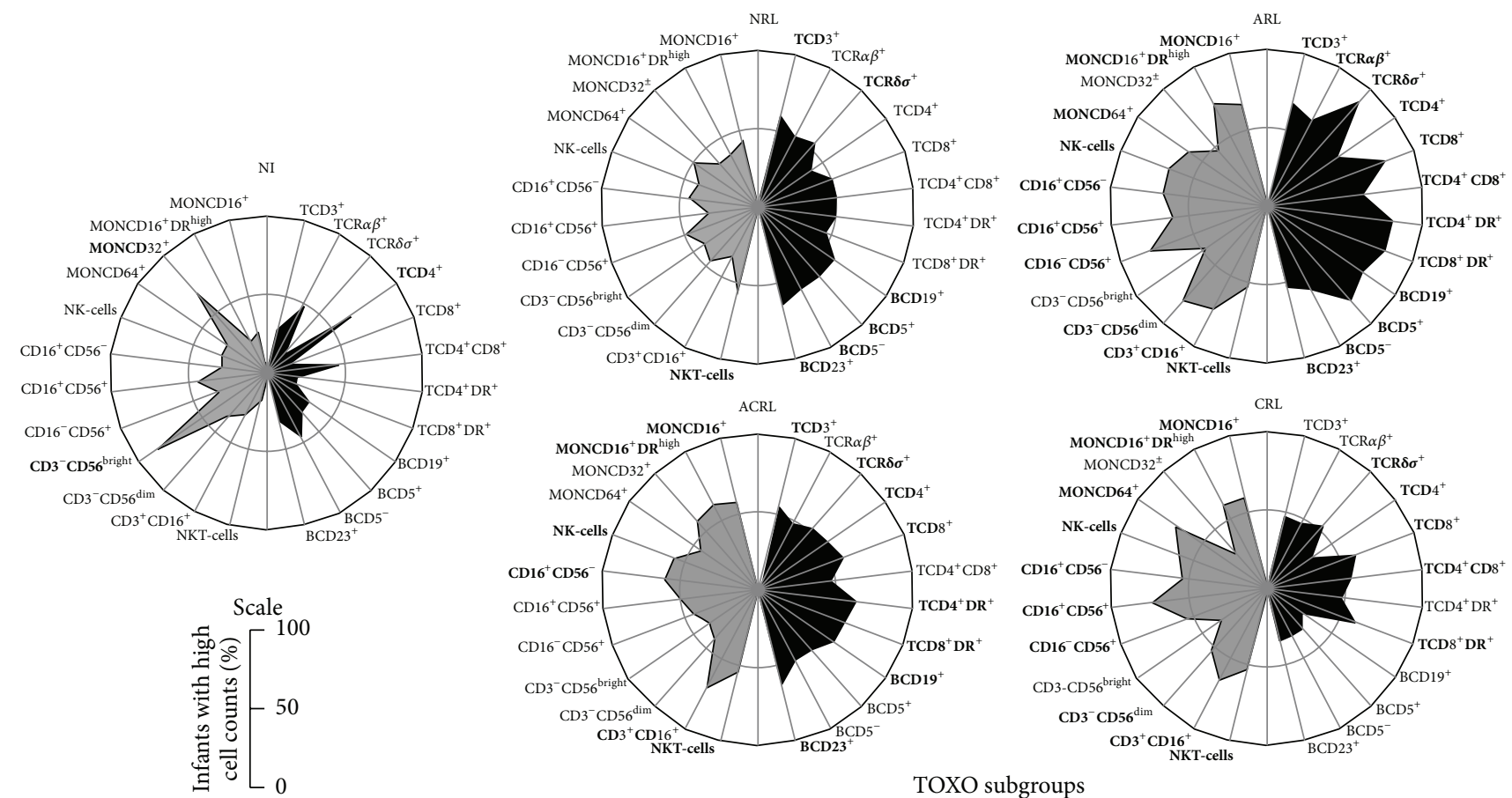

TOXO subgroups

$\square$ Innate

adaptive

(b)

FIGURE 4: Biomarker signatures of innate and adaptive immunity in the peripheral blood of infants with congenital toxoplasmosis categorized as no retinochoroidal lesions (NRL), active retinochoroidal lesions (ARL), active/cicatricial retinochoroidal lesions (ACRL), and cicatricial retinochoroidal lesions (CRL) compared to noninfected controls (NI). (a) Gray-scale diagrams were assembled using the global median value of each cell subset as the cut-off mark to tag each infant as presenting "low" or "high" (innate; adaptive) levels of a given cell population. The frequency (\%) of infants displaying high cell counts is provided, and the relevant data $(>50 \%)$ are underscored in bold/underline format. (b) The radar charts summarize the biomarker signature of innate and adaptive immunity, where each axis displays the proportion of infants with high levels of a given cell population. The relevant data $(>50 \%)$ are underscored in bold/underline format. 

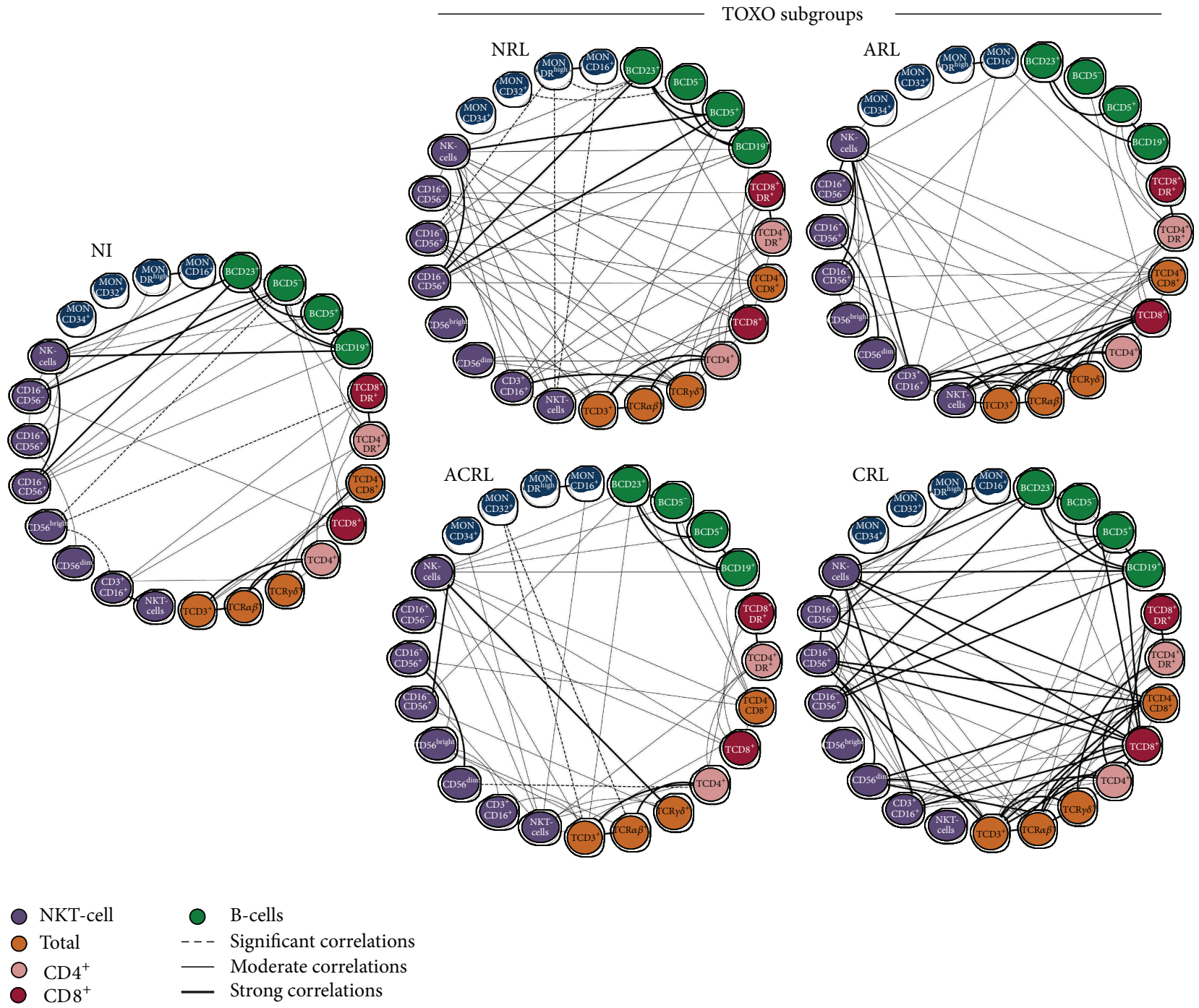

FIGURE 5: Biomarker networks of innate and adaptive immunity in the peripheral blood of infants with congenital toxoplasmosis categorized as no retinochoroidal lesions (NRL), active retinochoroidal lesions (ARL), active/cicatricial retinochoroidal lesions (ACRL), and cicatricial retinochoroidal lesions (CRL) compared to noninfected controls (NI). Networks were assembled to assess the association between leukocyte subpopulations, including monocytes, NK- and NKT-cells, T-cells (total, $\mathrm{CD}^{+}$, and $\mathrm{CD} 8^{+}$), and B-cells. Significant correlations at $P<0.05$ are highlighted by connecting edges to underscore negative, moderate, and strong indexes.

and/or atypical/recombinant genotypes leads to different manifestation of ocular toxoplasmosis was not confirmed by our parasitology team, as shown by Carneiro et al., 2013 [19]. Moreover, preliminary results regarding IgM reactivity as well as IgG avidity do not support the hypothesis that time of infection during pregnancy may influence the occurrence of distinct patterns of retinochoroidal lesions (paper in preparation). The development of an adequate innate immune response is important for infection control and reduction of toxoplasmosis-associated injuries, primarily retinochoroiditis. However, the initial stages of congenital infection are unclear, and most studies mainly refer to work with experimental models [20-22]. The present study is a great opportunity to understand the major and minor changes in peripheral blood leukocyte subpopulations in infants with congenital toxoplasmosis. Although the analysis of in vitro $T$. gondii-specific immune response is highly relevant to understand the role of the parasite-derived antigens essential to elucidate the mechanism underlying the immunopathogenesis of ocular toxoplasmosis, we believe that the ex vivo analysis particularly in the absence of exogenous stimuli is highly relevant to map the events that take place in vivo and may point out putative biomarkers useful to comprehend the systemic network involved in the immunopathogenesis of ocular toxoplasmosis.

Infants were selected through a newborn screening program, and therefore, no information about gestational age when the congenital infection occurred was available. Our results showed an increase in the populations of monocytes and lymphocytes in infants with congenital toxoplasmosis. It is known that monocyte recruitment is essential in restricting the growth of $T$. gondii in murine models of 
toxoplasmosis $[6,23]$. However, other studies show that these cells as well as dendritic cells are strong candidates for the intracellular transport of $T$. gondii in the blood as a "Trojan Horse" [24]. Moreover, the activity of monocytes must be carefully controlled because excessive production of inflammatory cytokines and nitric oxide (NO) can result in severe immunopathology [25]. The increase in the population of monocytes was observed only in the active lesion groups, suggesting that the persistence of the immune response mediated by monocytes is directly related to the pathology observed in these infants.

After this previous analysis, we examined the changes in specific monocyte subsets. An increase in proinflammatory monocytes $\left(\mathrm{CD} 14^{+} \mathrm{CD} 16^{+} \mathrm{HLA}^{-\mathrm{DR}^{++}}\right.$) in infants with congenital toxoplasmosis was observed. Previous studies have shown that inflammatory monocytes produce IL-12 in vitro and in vivo when stimulated with T. gondii $[6,7]$, and it has also been proposed that these cells contribute to the direct control of T. gondii through the production of NO, which inhibits parasite replication [8]. Increased proinflammatory monocytes in infected infants, particularly in those with active retinochoroidal lesions, are indicative of a strong and persistent proinflammatory response.

NK-and NKT-cells are other innate populations involved in immunity against $T$. gondii that are increased in infants with congenital toxoplasmosis compared with noninfected children. Our results showed an increase in the population of CD56 ${ }^{\text {dim }}$ cells in infants with active lesions when compared with an important decrease in the immunoregulatory NK subset, expressing CD56 $6^{\text {bright }}$. The increase in this population and in subsets of NK- and NKT-cells is an important feature of the innate immune responses against the parasite [26].

Analysis of the adaptive immune response showed that $\mathrm{CD}^{+} \mathrm{T}$ lymphocytes are apparently associated with the active lesion phenotype. Although several studies have demonstrated the importance of $\mathrm{CD}^{+}$T-cells in infection control, the production of proinflammatory cytokines, mainly by $\mathrm{CD} 4^{+} \mathrm{T}$ cells, is related to the morbidity of toxoplasmosis [27, 28]. Moreover, we observed that an increase in $\mathrm{CD}^{+} \mathrm{T}$-cells was associated with the presence of retinochoroiditis in infants. $\mathrm{CD}^{+} \mathrm{T}$-cells play a major role as effector lymphocytes against the parasite [29] and in killing infected macrophages and macrophages exposed to soluble parasite antigens [30]. Our results show that the increase in $\mathrm{CD}^{+}$T-cells could also be an important biomarker of morbidity in infected infants.

The results observed in infected infants suggest maturation of the immune response against $T$. gondii. The increases in lymphocyte populations and in subpopulations of monocytes and NK-cells are important in controlling parasitemia. However, exacerbation of the proinflammatory response may also be damaging to infants and, therefore, a determining factor in the pathology observed. Only infants with active lesions showed increased leukocyte counts (specifically monocytes, NK-cells, and lymphocytes). Moreover, the same children also showed increased subpopulations of proinflammatory monocytes and active NK-cells. It is important to consider, however, that future studies with proper validation of the immunological subsets are still needed in order to support their predictive value and specificity as putative biomarkers of ocular involvement in congenital toxoplasmosis.

\section{Conclusion}

Studies on the immune response in human infections by $T$. gondii, particularly in newborns, are rare. This work provides important findings regarding the immune response to congenital toxoplasmosis, which indicated immunomodulation possibly associated with local control of retinochoroiditis. Future studies with proper validation of the immunological subsets are still needed in order to support their predictive value and specificity as putative biomarkers in the ocular congenital toxoplasmosis.

\section{Conflict of Interests}

The authors declare that there is no conflict of interests regarding the publication of this paper.

\section{Authors' Contribution}

Anderson Silva Machado and Ana Carolina Aguiar Vasconcelos Carneiro contributed equally to this work.

\section{Acknowledgments}

This work was supported by Fundação de Amparo à Pesquisa do Estado de Minas Gerais (FAPEMIG), Conselho Nacional de Desenvolvimento Científico e Tecnológico (CNPq), Secretaria de Saúde de Minas Gerais (SES-MG), and Núcleo de Ações e Pesquisa em Apoio Diagnóstico (NUPAD). CDRJG received fellowship from FAPEMIG-PMPD program. Ricardo Wagner Almeida Vitor, Andréa TeixeiraCarvalho, and Olindo Assis Martins-Filho are CNPq research fellows. The authors thank Rosalida Estevan Nazar Lopes for her technical assistance. The "UFMG Congenital Toxoplasmosis Brazilian Group" was responsible in their areas of expertise for the identification, treatment and followup of the children with congenital toxoplasmosis included in the study entitled "Newborn Screening for Congenital Toxoplasmosis in the State of Minas Gerais". The members of UFMG Congenital Toxoplasmosis Brazilian Group (UFMG CTBG) include Ana Carolina Aguiar Vasconcelos Carneiro, Ph.D., Department of Parasitology, Institute of Biological Sciences, UFMG; Daniel Vitor Vasconcelos-Santos, M.D. and Ph.D., Uveitis Unit, Hospital São Geraldo, Hospital das Clínicas, UFMG; Danuza O. Machado Azevedo, M.D. and Ph.D., Uveitis Unit, Hospital São Geraldo, Hospital das Clínicas, UFMG; Ericka V. Machado Carellos, M.D. and Ph.D., Department of Paediatrics, School of Medicine, UFMG; Fernando Orefice, M.D. and Ph.D., Uveitis Unit, Hospital São Geraldo, Hospital das Clínicas, UFMG; Gláucia Manzan Queriroz Andrade, M.D. and Ph.D., Department of Paediatrics, School of Medicine, UFMG; José Nélio Januário, M.D. and M.S., Department of Internal Medicine, School of Medicine, NUPAD, UFMG; Luciana Macedo Resende, Ph.D., 
Department of Phonoaudiology, School of Medicine, UFMG; Olindo Assis Martins-Filho, M.S. and Ph.D., Centro de Pesquisas René Rachou, FIOCRUZ, Belo Horizonte, Brazil; Ricardo Wagner Almeida Vitor, M.S. and Ph.D., Department of Parasitology, Institute of Biological Sciences, UFMG; Roberta M. Castro Romanelli, M.D. and Ph.D., Department of Paediatrics, School of Medicine, UFMG; Waleska Teixeira Caiaffa, M.D., M.P.H., and ScD, Department of Preventive, Medicine, School of Medicine, UFMG.

\section{References}

[1] G. N. Holland, "Ocular toxoplasmosis: a global reassessment: part II: disease manifestations and management," The American Journal of Ophthalmology, vol. 137, no. 1, pp. 1-17, 2004.

[2] R. E. Gilbert, K. Freeman, E. G. Lago et al., "Ocular sequelae of congenital toxoplasmosis in Brazil compared with Europe," PLoS Neglected Tropical Diseases, vol. 2, no. 8, article e277, 2008.

[3] D. V. Vasconcelos-Santos, D. O. Machado Azevedo, W. R. Campos et al., "Congenital toxoplasmosis in Southeastern Brazil: results of early ophthalmologic examination of a large cohort of neonates," Ophthalmology, vol. 116, no. 11, pp. 2199.e12205.e1, 2009.

[4] C. D. Dupont, D. A. Christian, and C. A. Hunter, "Immune response and immunopathology during toxoplasmosis," Seminars in Immunopathology, vol. 34, no. 6, pp. 793-813, 2012.

[5] S. K. Bliss, B. A. Butcher, and E. Y. Denkers, "Rapid recruitment of neutrophils containing prestored IL-12 during microbial infection," The Journal of Immunology, vol. 165, no. 8, pp. 45154521, 2000.

[6] D. G. Mordue and L. D. Sibley, "A novel population of Gr-1 ${ }^{+}$activated macrophages induced during acute toxoplasmosis," Journal of Leukocyte Biology, vol. 74, no. 6, pp. 1015-1025, 2003.

[7] I. R. Dunay, A. Fuchs, and L. David Sibley, "Inflammatory monocytes but not neutrophils are necessary to control infection with Toxoplasma gondii in mice," Infection and Immunity, vol. 78, no. 4, pp. 1564-1570, 2010.

[8] I. R. Dunay and L. D. Sibley, "Monocytes mediate mucosal immunity to Toxoplasma gondii," Current Opinion in Immunology, vol. 22, no. 4, pp. 461-466, 2010.

[9] E. D. Tait, K. A. Jordan, C. D. Dupont et al., "Virulence of Toxoplasma gondii is associated with distinct dendritic cell responses and reduced numbers of activated $\mathrm{CD}^{+} \mathrm{T}$ cells," Journal of Immunology, vol. 185, no. 3, pp. 1502-1512, 2010.

[10] J. H. Yamamoto, A. L. Vallochi, C. Silveira et al., "Discrimination between patients with acquired toxoplasmosis and congenital toxoplasmosis on the basis of the immune response to parasite antigens," Journal of Infectious Diseases, vol. 181, no. 6, pp. 20182022, 2000.

[11] F. Fatoohi, G. J. N. Cozon, M. Wallon, L. Kodjikian, and F. Peyron, "Systemic T cell response to Toxoplasma gondii antigen in patients with ocular toxoplasmosis," Japanese Journal of Ophthalmology, vol. 50, no. 2, pp. 103-110, 2006.

[12] P. Shannon, A. Markiel, O. Ozier et al., "Cytoscape: a software Environment for integrated models of biomolecular interaction networks," Genome Research, vol. 13, no. 11, pp. 2498-2504, 2003.
[13] R. Taylor, "Interpretation of the correlation coefficient: a basic review," Journal of Diagnostic Medical Sonography, vol. 6, no. 1, pp. 35-39, 1990.

[14] E. Delair, P. Latkany, A. G. Noble, P. Rabiah, R. McLeod, and A. Brézin, "Clinical manifestations of ocular toxoplasmosis," Ocular Immunology and Inflammation, vol. 19, no. 2, pp. 91-102, 2011.

[15] T. R. Olariu, J. S. Remington, R. McLeod, A. Alam, and J. G. Montoya, "Severe congenital toxoplasmosis in the United States: clinical and serologic findings in untreated infants," Pediatric Infectious Disease Journal, vol. 30, no. 12, pp. 1056-1061, 2011.

[16] L. M. Weiss and J. P. Dubey, "Toxoplasmosis: a history of clinical observations," International Journal for Parasitology, vol. 39, no. 8, pp. 895-901, 2009.

[17] D. G. MacK, J. J. Johnson, F. Roberts et al., "HLA-class II genes modify outcome of Toxoplasma gondii infection," International Journal for Parasitology, vol. 29, no. 9, pp. 1351-1358, 1999.

[18] M. S. Dutra, S. R. Béla, A. L. Peixoto-Rangel et al., "Association of a NOD2 gene polymorphism and T-helper 17 cells with presumed ocular toxoplasmosis," Journal of Infectious Diseases, vol. 207, no. 1, pp. 152-163, 2013.

[19] A. C. A. V. Carneiro, G. M. Andrade, J. G. L. Costa et al., "Genetic characterization of Toxoplasma gondii revealed highly diverse genotypes for isolates from newborns with congenital toxoplasmosis in Southeastern Brazil," Journal of Clinical Microbiology, vol. 51, no. 3, pp. 901-907, 2013.

[20] P. Escoffier, J. C. Jeanny, C. Marinach-Patrice et al., “Toxoplasma gondii: flat-mounting of retina as a new tool for the observation of ocular infection in mice," Experimental Parasitology, vol. 126, no. 2, pp. 259-262, 2010.

[21] A. Kikumura, T. Ishikawa, and K. Norose, "Kinetic analysis of cytokines, chemokines, chemokine receptors and adhesion molecules in murine ocular toxoplasmosis," British Journal of Ophthalmology, vol. 96, no. 9, pp. 1259-1267, 2012.

[22] A. Sauer, E. Rochet, I. Lahmar et al., "The local immune response to intraocular Toxoplasma re-challenge: less pathology and better parasite control through Treg/Th1/Th2 induction," International Journal for Parasitology, vol. 43, no. 9, pp. 721-728, 2013.

[23] P. M. Robben, M. LaRegina, W. A. Kuziel, and L. D. Sibley, "Recruitment of Gr-1+ monocytes is essential for control of acute toxoplasmosis," Journal of Experimental Medicine, vol. 201, no. 11, pp. 1761-1769, 2005.

[24] S. M. Lachenmaier, M. A. Deli, M. Meissner, and O. Liesenfeld, "Intracellular transport of Toxoplasma gondii through the blood-brain barrier," Journal of Neuroimmunology, vol. 232, no. 1-2, pp. 119-130, 2011.

[25] D. M. Mosser, "The many faces of macrophage activation," Journal of Leukocyte Biology, vol. 73, no. 2, pp. 209-212, 2003.

[26] A. R. French, E. B. Holroyd, L. Yang, S. Kim, and W. M. Yokoyama, "IL-18 acts synergistically with IL-15 in stimulating natural killer cell proliferation," Cytokine, vol. 35, no. 5-6, pp. 229-234, 2006.

[27] R. T. Gazzinelli, M. Wysocka, S. Hieny et al., "In the absence of endogenous IL-10, mice acutely infected with Toxoplasma gondii succumb to a lethal immune response dependent on $\mathrm{CD}^{+} \mathrm{T}$ cells and accompanied by overproduction of IL-12, IFN-gamma and TNF-alpha," The Journal of Immunology, vol. 157, pp. 798-805, 1996. 
[28] F. Lu, S. Huang, and L. H. Kasper, "CD4 ${ }^{+} \mathrm{T}$ cells in the pathogenesis of murine ocular toxoplasmosis," Infection and Immunity, vol. 72, no. 9, pp. 4966-4972, 2004.

[29] Y. Suzuki, M. A. Orellana, R. D. Schreiber, and J. S. Remington, "Interferon- $\gamma$ : the major mediator of resistance against Toxoplasma gondii," Science, vol. 240, no. 4851, pp. 516-518, 1988.

[30] F. T. Hakim, R. T. Gazzinelli, E. Denkers, S. Hieny, G. M. Shearer, and A. Sher, "CD8 ${ }^{+} \mathrm{T}$ cells from mice vaccinated against Toxoplasma gondii are cytotoxic for parasite-infected or antigen-pulsed host cells," Journal of Immunology, vol. 147, no. 7, pp. 2310-2316, 1991. 


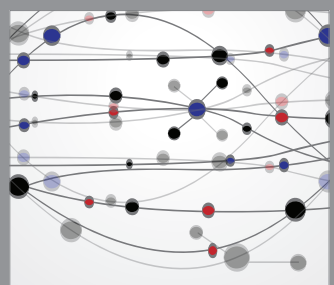

The Scientific World Journal
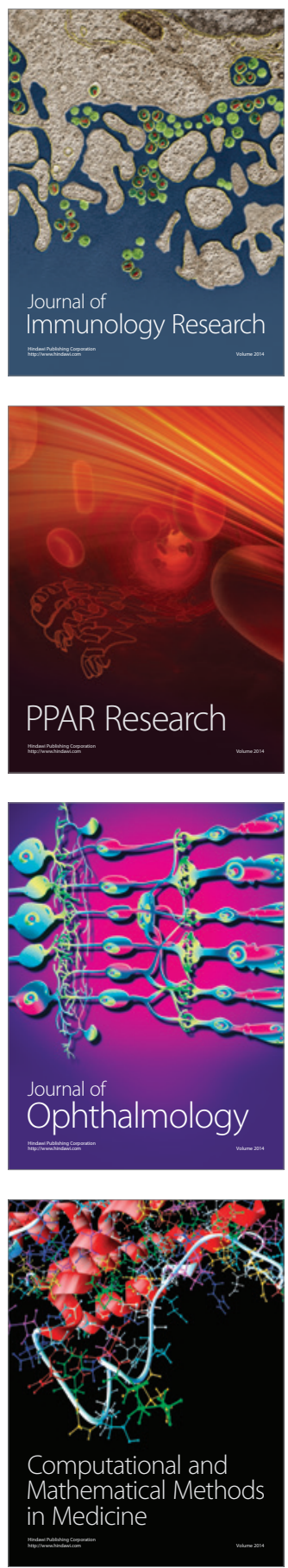

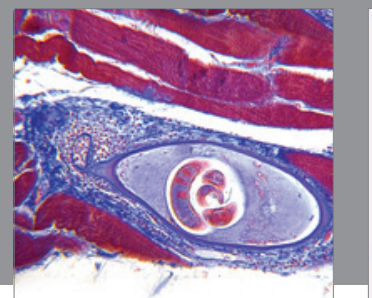

Gastroenterology

Research and Practice
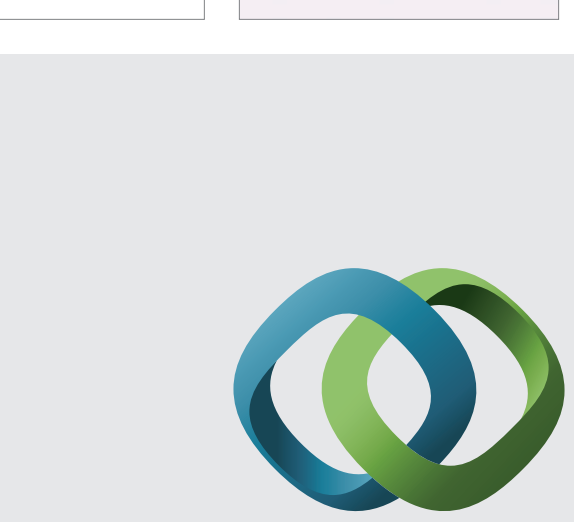

\section{Hindawi}

Submit your manuscripts at

http://www.hindawi.com
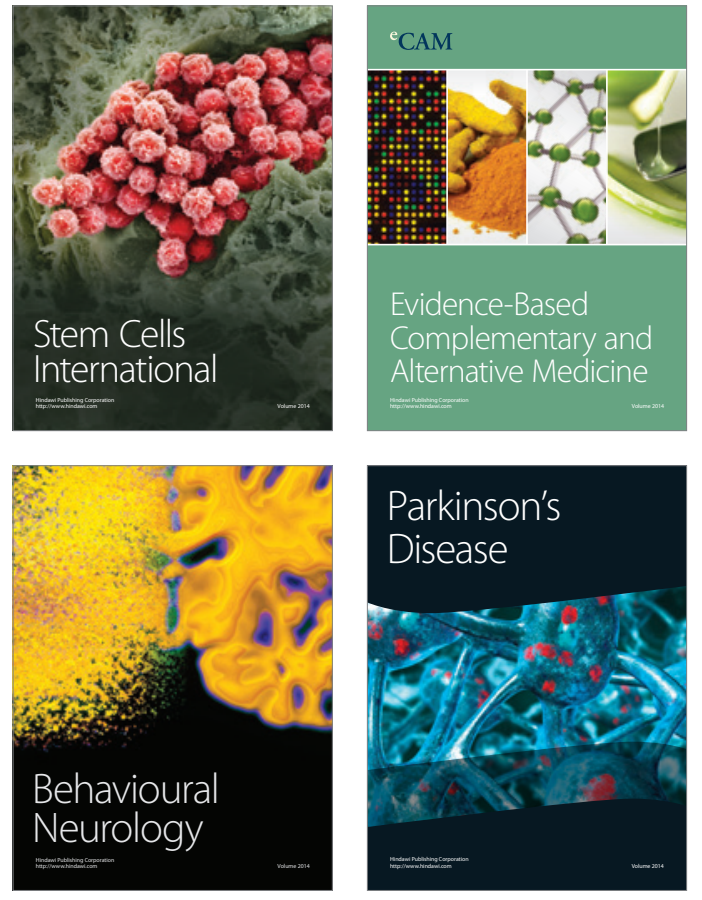
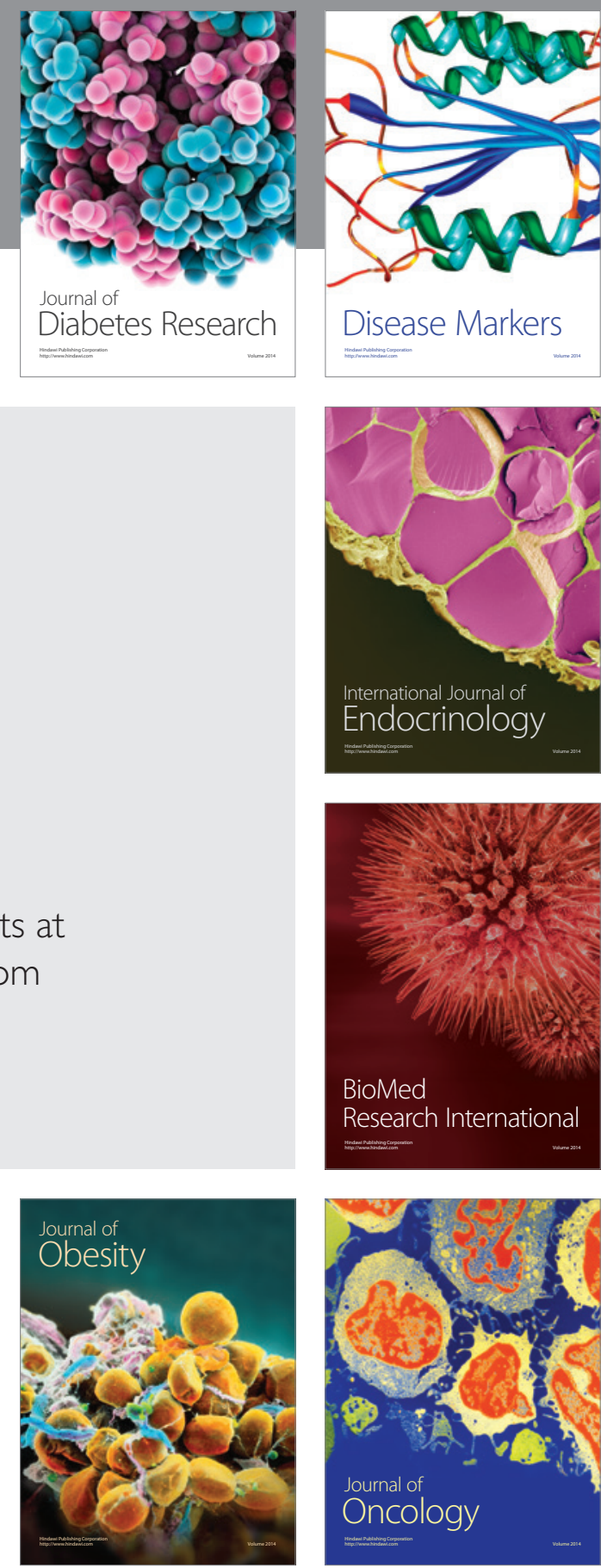

Disease Markers
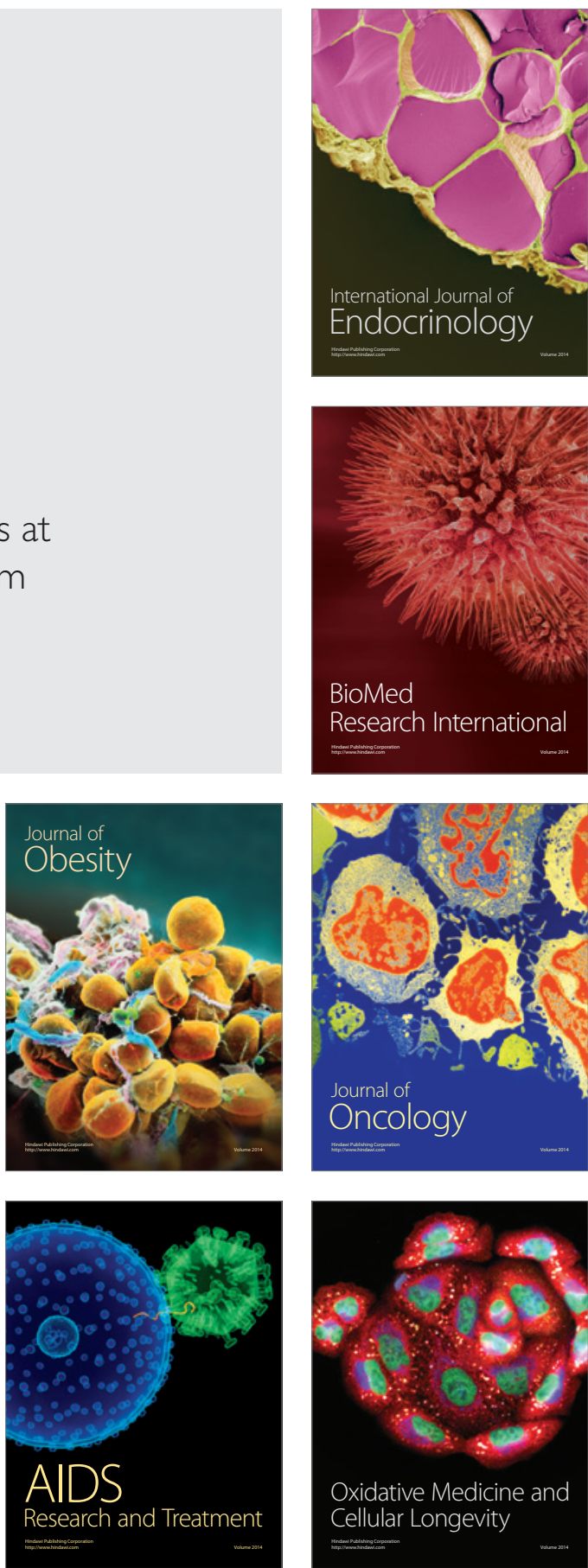